\title{
BILANGAN KROMATIK LOKASI UNTUK JOIN DARI DUA GRAF
}

\author{
YULI ERITA \\ Program Studi Matematika, \\ Pascasarjana Fakultas Matematika dan Ilmu Pengetahuan Alam, Universitas Andalas, \\ Kampus UNAND Limau Manis Padang, Indonesia,
}

\begin{abstract}
Let $f$ be a proper $k$-coloring of a connected graph $G$ and $\Pi=\left(V_{1}, \ldots, V_{k}\right)$ be an ordered partition of $V(G)$ into the resulting color classes. For a vertex $v$ of $G$, the color code of $v$ with respect to $\Pi$ is defined to be the ordered $k$-tuple

$$
c_{\Pi}(v)=\left(d\left(v, V_{1}\right), d\left(v, V_{2}\right), \ldots, d\left(v, V_{k}\right)\right),
$$

where $d\left(v, V_{i}\right)=\min \left\{d(v, x) \mid x \in V_{i}\right\}, 1 \leq i \leq k$. If distinct vertices have distinct color codes, then $f$ is called a locating coloring. The minimum number of colors needed in a locating coloring of $G$ is the locating chromatic number of $G$, and denoted by $\chi_{L}(G)$. In this paper, we study the locating chromatic number of the join of some graphs.
\end{abstract}

Kata Kunci: Locating coloring, locating chromatic number, join

\section{Pendahuluan}

Suatu pewarnaan titik (vertex coloring) pada graf $G$ adalah suatu pemetaan $c: V \rightarrow$ $\mathbb{N}$ sehingga $c(v) \neq c(w)$ jika $v$ dan $w$ bertetangga. Bilangan kromatik (chromatic number) dari $G$ adalah bilangan asli terkecil $n$ sedemikian sehingga, jika titik-titik di $G$ diwarnai dengan $n$ warna, maka tidak ada titik yang bertetangga mempunyai warna yang sama. Bilangan kromatik dari $G$ dinotasikan dengan $\chi(G)$. Misalkan $\chi(G)=n$, ini berarti titik-titik di $G$ paling kurang diwarnai dengan $n$ warna, dan tidak dapat diwarnai dengan $n-1$ warna.

Kelas warna pada $G$, dinotasikan dengan $C_{i}$, merupakan himpunan titik-titik yang berwarna $i$ dan $1 \leq i \leq k$. Misalkan $\Pi=C_{1}, C_{2}, \ldots, C_{k}$ merupakan partisi terurut dari $V(G)$ berdasarkan suatu pewarnaan titik, maka representasi $v$ terhadap $\Pi$ disebut kode warna dari $v$, dinotasikan dengan $c_{\Pi}(v)$. Kode warna (color code) $c_{\Pi}(v)$ dari suatu titik $v \in V(G)$ didefinisikan sebagai $k$ vektor:

$$
c_{\Pi}(v)=\left(d\left(v, C_{1}\right), d\left(v, C_{2}\right), \ldots, d\left(v, C_{k}\right)\right),
$$

di mana $d\left(v, C_{i}\right)=\min \left\{d(v, x) \mid x \in C_{i}\right\}$. Jika setiap titik yang berbeda di $G$ memiliki kode yang berbeda, maka $c$ disebut pewarnaan lokasi (locating coloring) bagi $G$. Oleh karena itu, pewarnaan lokasi pada graf $G$ adalah pewarnaan yang membedakan setiap titik di $G$ berdasarkan jaraknya terhadap warna yang dihasilkan. Jumlah minimum warna yang digunakan pada pewarnaan lokasi dari graf $G$ disebut bilangan kromatik lokasi (locating chromatic number). Karena setiap pewarnaan lokasi merupakan suatu pewarnaan, maka $\chi(G) \leq \chi_{L}(G)$ untuk setiap graf terhubung $G$. 
Untuk lebih jelasnya perhatikan contoh berikut. Misal diberikan suatu graf $G$ dengan orde $n=8$ dan diberikan pewarnaan seperti pada Gambar 1, dengan kelas warna $C_{1}=\left\{v_{1}, v_{5}\right\}, C_{2}=\left\{v_{3}, v_{7}\right\}, C_{3}=\left\{v_{2}, v_{6}\right\}$, dan $C_{4}=\left\{v_{4}, v_{8}\right\}$.

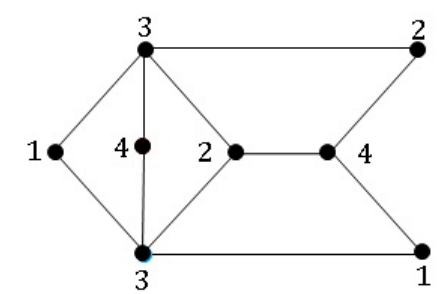

Gambar 1. Pewarnaan $c^{\prime}$ pada Graf $G$

Kode warna dari titik-titik di graf $G$ terhadap $\Pi^{\prime}=\left\{C_{1}, C_{2}, C_{3}, C_{4}\right\}$ adalah

$$
\begin{aligned}
& c_{\Pi^{\prime}}\left(v_{1}\right)=\left(d\left(v_{1}, C_{1}\right), d\left(v_{1}, C_{2}\right), d\left(v_{1}, C_{3}\right), d\left(v_{1}, C_{4}\right)\right)=(0,2,1,2), \\
& c_{\Pi^{\prime}}\left(v_{2}\right)=\left(d\left(v_{2}, C_{1}\right), d\left(v_{2}, C_{2}\right), d\left(v_{2}, C_{3}\right), d\left(v_{2}, C_{4}\right)\right)=(1,1,0,1), \\
& c_{\Pi^{\prime}}\left(v_{3}\right)=\left(d\left(v_{3}, C_{1}\right), d\left(v_{3}, C_{2}\right), d\left(v_{3}, C_{3}\right), d\left(v_{3}, C_{4}\right)\right)=(2,0,1,1), \\
& c_{\Pi^{\prime}}\left(v_{4}\right)=\left(d\left(v_{4}, C_{1}\right), d\left(v_{4}, C_{2}\right), d\left(v_{4}, C_{3}\right), d\left(v_{4}, C_{4}\right)\right)=(1,1,2,0), \\
& c_{\Pi^{\prime}}\left(v_{5}\right)=\left(d\left(v_{5}, C_{1}\right), d\left(v_{5}, C_{2}\right), d\left(v_{5}, C_{3}\right), d\left(v_{5}, C_{4}\right)\right)=(0,2,1,1), \\
& c_{\Pi^{\prime}}\left(v_{6}\right)=\left(d\left(v_{6}, C_{1}\right), d\left(v_{6}, C_{2}\right), d\left(v_{6}, C_{3}\right), d\left(v_{6}, C_{4}\right)\right)=(1,1,0,1), \\
& c_{\Pi^{\prime}}\left(v_{7}\right)=\left(d\left(v_{7}, C_{1}\right), d\left(v_{7}, C_{2}\right), d\left(v_{7}, C_{3}\right), d\left(v_{7}, C_{4}\right)\right)=(2,0,1,1), \\
& c_{\Pi^{\prime}}\left(v_{8}\right)=\left(d\left(v_{8}, C_{1}\right), d\left(v_{8}, C_{2}\right), d\left(v_{8}, C_{3}\right), d\left(v_{8}, C_{4}\right)\right)=(2,2,1,0) .
\end{aligned}
$$

Pewarnaan dengan empat warna pada graf $G$ bukan suatu pewarnaan lokasi karena terdapat titik-titik dengan kode warna sama. Sebaliknya pewarnaan $c^{\prime \prime}$ pada $G$ seperti terlihat pada Gambar 1 merupakan pewarnaan lokasi pada graf $G$ karena setiap titik pada graf $G$ memiliki kode warna berbeda terhadap $\Pi^{\prime \prime}=\left\{C_{1}, C_{2}, C_{3}, C_{4}, C_{5}\right\}$. Kode warna dari titik-titik pada $G$ dengan lima pewarnaan adalah

$$
\begin{aligned}
& c_{\Pi^{\prime \prime}}^{\prime}\left(v_{1}\right)=\left(d\left(v_{1}, C_{1}\right), d\left(v_{1}, C_{2}\right), d\left(v_{1}, C_{3}\right), d\left(v_{1}, C_{4}\right), d\left(v_{1}, C_{5}\right)\right)=(0,1,1,2,2), \\
& c_{\Pi^{\prime \prime}}^{\prime}\left(v_{2}\right)=\left(d\left(v_{2}, C_{1}\right), d\left(v_{2}, C_{2}\right), d\left(v_{2}, C_{3}\right), d\left(v_{2}, C_{4}\right), d\left(v_{2}, C_{5}\right)\right)=(1,0,1,1,1), \\
& c_{\Pi^{\prime \prime}}^{\prime}\left(v_{3}\right)=\left(d\left(v_{3}, C_{1}\right), d\left(v_{3}, C_{2}\right), d\left(v_{3}, C_{3}\right), d\left(v_{3}, C_{4}\right), d\left(v_{3}, C_{5}\right)\right)=(2,1,0,1,2), \\
& c_{\Pi^{\prime \prime}}^{\prime}\left(v_{4}\right)=\left(d\left(v_{4}, C_{1}\right), d\left(v_{4}, C_{2}\right), d\left(v_{4}, C_{3}\right), d\left(v_{4}, C_{4}\right), d\left(v_{4}, C_{5}\right)\right)=(3,2,1,0,1), \\
& c_{\Pi^{\prime \prime}}^{\prime}\left(v_{5}\right)=\left(d\left(v_{5}, C_{1}\right), d\left(v_{5}, C_{2}\right), d\left(v_{5}, C_{3}\right), d\left(v_{5}, C_{4}\right), d\left(v_{5}, C_{5}\right)\right)=(2,3,1,1,0), \\
& c_{\Pi^{\prime \prime}}^{\prime}\left(v_{6}\right)=\left(d\left(v_{6}, C_{1}\right), d\left(v_{6}, C_{2}\right), d\left(v_{6}, C_{3}\right), d\left(v_{6}, C_{4}\right), d\left(v_{6}, C_{5}\right)\right)=(1,2,0,1,1), \\
& c_{\Pi^{\prime \prime}}^{\prime}\left(v_{7}\right)=\left(d\left(v_{7}, C_{1}\right), d\left(v_{7}, C_{2}\right), d\left(v_{7}, C_{3}\right), d\left(v_{7}, C_{4}\right), d\left(v_{7}, C_{5}\right)\right)=(2,1,1,1,0), \\
& c_{\Pi^{\prime \prime}}^{\prime}\left(v_{8}\right)=\left(d\left(v_{8}, C_{1}\right), d\left(v_{8}, C_{2}\right), d\left(v_{8}, C_{3}\right), d\left(v_{8}, C_{4}\right), d\left(v_{8}, C_{5}\right)\right)=(2,1,1,0,2) .
\end{aligned}
$$




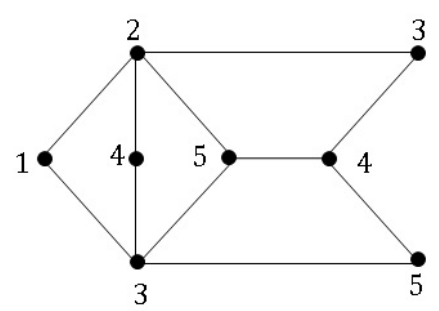

Gambar 2. Pewarnaan c" pada Graf $G$

Dari contoh di atas dapat dilihat bahwa pewarnaan $c$ " yang menggunakan lima warna pada $G$ adalah pewarnaan lokasi dengan kardinalitas paling kecil. Oleh karena itu, bilangan kromatik lokasi dari graf $G, \chi_{L}(G)=5$.

Teorema 1.1. [5] Misal c suatu pewarnaan lokasi pada graf terhubung G. Jika u dan $v$ adalah titik-titik yang berbeda pada $G$ sedemikian sehingga, $d(u, w)=d(v, w)$ untuk setiap $w \in V(G)-\{u, v\}$ maka $c(u) \neq c(v)$. Dalam hal khusus, jika u dan $v$ adalah titik-titik yang tidak bertetangga pada $G$ sehingga $N(u)=N(v)$, maka $c(u) \neq c(v)$.

Bukti. Misalkan $c$ adalah suatu pewarnaan lokasi pada graf terhubung $G$ dan misalkan $\Pi=\left(C_{1}, C_{2}, \ldots, C_{k}\right)$ adalah partisi dari titik-titik $G$ ke dalam kelas warna $C_{i}$. Untuk suatu titik $u, v \in V(G)$, andaikan $c(u)=c(v)$ sedemikian sehingga titik $u$ dan $v$ berada dalam kelas warna yang sama, misal $C_{i}$ dari $\Pi$. Akibatnya, $d(u, C i)=d(v, C i)=0$. Karena $d(u, w)=d(v, w)$ untuk setiap $w \in V(G)\{u, v\}$, maka $d\left(u, C_{j}\right)=d\left(v, C_{j}\right)$ untuk setiap $j \neq i ; 1 \leq j \leq k$. Akibatnya, $c_{\Pi}(u)=c_{\Pi}(v)$ sehingga $c$ bukan pewarnaan lokasi. Dengan demikian, $c(u) \neq c(v)$.

\section{Bilangan Kromatik Lokasi Untuk Join dari Dua Graf}

Misalkan $G$ adalah suatu graf tanpa loop dan sisi ganda dengan himpunan titik $V(G)$ dan himpunan sisi $E(G)$. Suatu pewarnaan $k$-warna dari $G, k \in \mathbb{N}$, adalah suatu fungsi $f$ didefinisikan dari $V(G)$ pada $[k]=\{1,2, \ldots, 3\}$ sehingga setiap dua titik yang bertetangga mempunyai warna yang berbeda.

Definisi 2.1. Misalkan $f$ adalah suatu k-pewarnaan dari suatu graf terhubung $G$ dan $\Pi=\left(C_{1}, C_{2}, \ldots, C_{k}\right)$ adalah partisi terurut dari $V(G)$ dalam kelas warna yang dihasilkan. Untuk suatu titik $v$ di $G$, kode warna dari $v$ yang terkait dengan $\Pi$ didefinisikan sebagai berikut

$$
c_{\Pi}(v)=\left(d\left(v, C_{1}\right), d\left(v, C_{2}\right), \ldots, d\left(v, C_{k}\right)\right) .
$$

Jika titik yang berbeda pada $G$ mempunyai warna yang berbeda maka $f$ disebut pewarnaan lokasi dari $G$. Bilangan kromatik lokasi, dinotasikan dengan $\chi_{L}(G)$, adalah banyak warna minimum dalam pewarnaan lokasi $G$.

Koordinat ke- $i$ pada kode warna setiap titik dalam kelas warna $C_{i}$ adalah nol dan koordinat lainnya selain nol. Oleh karena itu suatu pewarnaan merupakan suatu 
pewarnaan lokasi jika kode warna dari titik titik dalam setiap kelas warna selalu berbeda.

\section{Bilangan Kromatik Lokasi Tetangga}

Bilangan kromatik lokasi tetangga mempunyai hubungan yang sangat dekat dengan bilangan kromatik lokasi. Bilangan kromatik lokasi tetangga juga bisa digunakan untuk graf tidak terhubung.

Definisi 3.1. [2] Misalkan $f$ adalah suatu k-pewarnaan pada graf G. Jika untuk setiap dua titik yang berbeda $u$ dan $v$ berwarna sama, dengan $f\left(N_{G}(u)\right) \neq f\left(N_{G}(v)\right)$, maka $f$ disebut sebagai suatu pewarnaan lokasi tetangga dari $G$. Bilangan kromatik lokasi tetangga, dinotasikan dengan $\chi_{L 2}(G)$, adalah banyak warna minimum pada pewarnaan lokasi tetangga pada $G$.

Misalkan terdapat suatu graf $G$ dengan pewarnaan seperti pada Gambar 3.

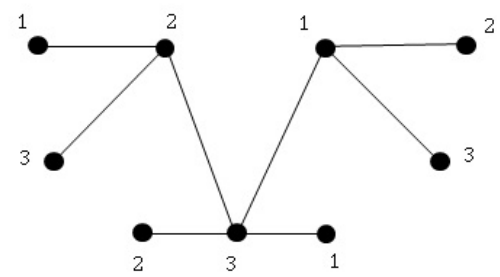

Gambar 3. Pewarnaan pada graf $G$

Dari Gambar 3 terlihat bahwa $v_{1}, v_{3}$ dan $v_{9}$ berwarna sama dengan $f\left(N_{G}\left(v_{1}\right)\right)=$ $\{2\}, f\left(N_{G}\left(v_{3}\right)\right)=\{2,3\}$ dan $f\left(N_{G}\left(v_{9}\right)\right)=\{3\}$, titik $v_{2}, v_{4}$ dan $v_{7}$ juga berwarna sama, dengan himpunan warna tetangganya $f\left(N_{G}\left(v_{2}\right)\right)=\{1,3\}, f\left(N_{G}\left(v_{4}\right)\right)=\{1\}$, $f\left(N_{G}\left(v_{7}\right)\right)=\{3\}$, titik $v_{5}, v_{6}$ dan $v_{8}$ juga berwarna sama, dan himpunan warna tetangganya $f\left(N_{G}\left(v_{5}\right)=\{2\}\right), f\left(N_{G}\left(v_{6}\right)\right)=\{1\}, f\left(N_{G}\left(v_{8}\right)\right)=\{1,2\}$. Karena setiap titik yang berwarna sama pada $G$ mempunyai himpunan warna tetangga yang berbeda maka pewarnaan pada $G$ adalah suatu pewarnaan lokasi tetangga dengan menggunakan 3-warna.

Untuk melihat hubungan antara parameter $\chi_{L}$ dan $\chi_{L 2}$, misalkan $f$ adalah suatu $k$-pewarnaan dari graf terhubung $G$ dan $\Pi=\left(V_{1}, V_{2}, \ldots, V_{k}\right)$ adalah suatu partisi terurut dari $V(G)$ dalam menghasilkan kelas warna. Pewarnaan $f$ adalah pewarnaan lokasi tetangga jika dan hanya jika titik yang berbeda pada $G$ mempunyai kode warna yang berbeda [2]. Selanjutnya, setiap pewarnaan lokasi tetangga pada $G$ adalah pewarnaan lokasi. Oleh karena itu $\chi_{L}(G) \leq \chi_{L 2}(G)$. Jika diameter $G$ paling besar dua, maka setiap pewarnaan lokasi dari $G$ adalah suatu pewarnaan lokasi tetangga dan oleh karena itu $\chi_{L 2}(G) \leq \chi_{L}(G)$. Karena itu diperoleh Proposisi 3.2 berikut ini. 
Proposisi 3.2. [2] Jika $G$ adalah suatu graf terhubung dengan diameter $\leq 2$, maka $\chi_{L}(G)=\chi_{L 2}(G)$.

Khusus untuk graf lengkap [2], $\chi_{L 2}\left(K_{n}\right)=n$ dan $\chi_{L 2}\left(K_{m, n}\right)=m+n$.

\section{Bilangan Kromatik Lokasi dan Operasi Join}

Pada bagian ini akan ditentukan kembali bilangan kromatik lokasi dari graf pertemanan, dan join dari graf lintasan, lingkaran, dan graf lengkap.

Teorema 4.1. [2] Untuk sebarang graf $G_{1}$ dan $G_{2}, \chi_{L}\left(G_{1}+G_{2}\right)=\chi_{L 2}\left(G_{1}\right)+$ $\chi_{L 2}\left(G_{2}\right)$.

Bukti. Diameter $\chi_{L}\left(G_{1}+G_{2}\right)$ paling besar dua, oleh karena itu berdasarkan Proposisi 3.2, $\chi_{L}\left(G_{1}+G_{2}\right)=\chi_{L 2}\left(G_{1}+G_{2}\right)$. Misalkan $k_{1}=\chi_{L 2}\left(G_{1}\right), k_{2}=\chi_{L 2}\left(G_{2}\right)$, dan $k=\chi_{L 2}\left(G_{1}+G_{2}\right)$. Misalkan juga $f$ adalah suatu pewarnaan lokasi tetangga dengan $k$-warna pada $\left(G_{1}+G_{2}\right)$. Titik-titik pada $G_{1}$ bertetangga dengan titik-titik pada $G_{2}$ dan oleh karena itu,

$$
\left\{f(u) \mid u \in V\left(G_{1}\right)\right\} \cap\left\{f(v) \mid v \in V\left(G_{2}\right)\right\}=\emptyset .
$$

Misalkan $k_{1}^{\prime}=|f(u)| u \in V\left(G_{1}\right) \mid$ dan $k_{2}^{\prime}=|f(v)| v \in V\left(G_{2}\right) \mid$. Dengan demikian, $k=k_{1}^{\prime}+k_{2}^{\prime}$. Asumsikan bahwa $u$ dan $u^{\prime}$ adalah dua titik di $G_{1}$ yang mempunyai warna yang sama. Karena $f$ adalah suatu pewarnaan lokasi tetangga dan $V\left(G_{2}\right) \subseteq$ $N_{G_{1}+G_{2}}(u) \cap N_{G_{1}+G_{2}}\left(u^{\prime}\right)$, maka diperoleh $f\left(N_{G_{1}}(u) \neq f\left(N_{G_{1}}\left(u^{\prime}\right)\right)\right.$. Hal ini berarti bahwa $f$ adalah suatu pewarnaan lokasi tetangga dengan $k_{1}^{\prime}$-warna pada $G_{1}$. Oleh karena itu $k_{1} \leq k_{1}^{\prime}$. Selanjutnya asumsikan bahwa $v$ dan $v^{\prime}$ adalah dua titik di $G_{2}$ yang berwarna sama. Karena $f$ adalah suatu pewarnaan lokasi tetangga dan $V\left(G_{1}\right) \subseteq N_{G_{1}+G_{2}}(v) \cap N_{G_{1}+G_{2}}\left(v^{\prime}\right)$, maka $f\left(N_{G_{2}}(v) \neq f\left(N_{G_{2}}\left(v^{\prime}\right)\right)\right.$. Hal ini berarti bahwa $f$ adalah suatu pewarnaan lokasi tetangga dengan $k_{2}^{\prime}$-warna pada $G_{2}$. Oleh karena itu $k_{2} \leq k_{2}^{\prime}$. Dengan demikian $k_{1}+k_{2} \leq k_{1}^{\prime}+k_{2}^{\prime}=k$.

Misalkan $f_{1}$ adalah suatu pewarnaan lokasi tetangga dengan $k_{1}$-warna pada $G_{1}$ dengan himpunan warna $\left\{1,2,3, \ldots, k_{1}\right\}$, dan $f_{2}$ adalah suatu pewarnaan lokasi tetangga dengan $k_{2}$-warna pada $G_{2}$ dengan himpunan warna $\left\{k_{1}+1, k_{1}+2, \ldots, k_{1}+\right.$ $\left.k_{2}\right\}$. Definisikan suatu pewarnaan $f^{\prime}$ dengan $k_{1}+k_{2}$-warna pada $G_{1}+G_{2}$ sebagai $f^{\prime}(u)=f_{1}(u)$ dimana $u \in V\left(G_{1}\right)$, dan $f^{\prime}(v)=f_{2}(u)$ dimana $v \in V\left(G_{2}\right)$. Jika $z_{1}$ dan $z_{2}$ adalah titik pada $G_{1}+G_{2}$ dengan $f^{\prime}\left(z_{1}\right)=f^{\prime}\left(z_{2}\right)$, maka $\left\{z_{1}, z_{2}\right\} \subseteq$ $V\left(G_{1}\right)$ atau $\left\{z_{1}, z_{2}\right\} \subseteq V\left(G_{2}\right)$. Tanpa mengurangi keumuman, asumsikan bahwa $\left\{z_{1}, z_{2}\right\} \subseteq V\left(G_{1}\right)$. Karena $f_{1}$ adalah suatu pewarnaan lokasi tetangga dengan $k_{1}$ warna dan $V\left(G_{2}\right) \subseteq N_{G_{1}+G_{2}}\left(z_{1}\right) \cap N_{G_{1}+G_{2}}\left(z_{2}\right)$, maka diperoleh $f\left(N_{G_{1}+G_{2}}\left(z_{1}\right)\right) \neq$ $f\left(N_{G_{1}+G_{2}}\left(z_{2}\right)\right)$. Ini berarti bahwa $f^{\prime}$ adalah suatu pewarnaan lokasi tetangga dengan $k_{1}+k_{2}$-pewarnaan pada $G_{1}+G_{2}$, dan oleh karena itu, $k \leq k_{1}+k_{2}$. Maka diperoleh bahwa $k=k_{1}+k_{2}$.

Misalkan terdapat dua bilangan bulat positif $m$ dan $t$, dan $G:=t K_{m}$, merupakan graf yang terdiri dari $t$ disjoin graf $K_{m}$. Suatu pewarnaan di $G$ adalah suatu pewarnaan lokasi tetangga jika dan hanya jika tidak terdapat dua komponen dengan 
himpunan warna yang sama. Untuk suatu bilangan bulat positif $k$, himpunan $[k]$ mempunyai subhimpunan yang berbeda dengan ukuran $m$ sebanyak $\left(\begin{array}{c}k \\ m\end{array}\right)$. Dengan demikian $\chi_{L 2}(G)=\min \left\{k \mid t \leq\left(\begin{array}{c}k \\ m\end{array}\right)\right\}$.

Proposisi 4.2. [2] Untuk suatu bilangan bulat positif $t$, misalkan $n:=2 t+1$, maka bilangan kromatik lokasi dari graf pertemanan $F_{r_{n}}$ adalah $1+\min \left\{k \mid t \leq\left(\begin{array}{l}k \\ 2\end{array}\right)\right\}$.

Bukti. Misal diberikan graf $F r_{n}=K_{1}+t K_{2}$. Banyak warna yang digunakan untuk mewarnai $t K_{m}$ adalah $\min \left\{k \mid t \leq\left(\begin{array}{c}k \\ m\end{array}\right)\right\}$. Oleh karena itu pewarnaan untuk suatu graf $t K_{2}$ adalah $\min \left\{k \mid t \leq\left(\begin{array}{c}k \\ 2\end{array}\right)\right\}$ dan warna minimum untuk $K_{1}$ adalah satu. Karena $K_{1}$ bertetangga dengan semua titik pada $t K_{2}$ maka warna titik pada $t K_{2}$ harus berbeda dengan warna titik di $K_{1}$. Akibatnya $\chi_{L}\left(F r_{n}\right)=1+\min \left\{k \mid t \leq\left(\begin{array}{l}k \\ 2\end{array}\right)\right\}$.

Misalkan $G \in\left\{P_{n}, C_{n}\right\}$. Pewarnaan $f$ di $G$ dapat direpresentasikan dengan $\left[f\left(v_{1}\right), f\left(v_{2}\right), \ldots, f\left(v_{n}\right)\right]$. Untuk $1 \leq n_{1} \leq n$, misalkan $f_{\left.\right|_{\left[n_{1}\right]}}=\left[f\left(v_{1}\right), f\left(v_{2}\right), \ldots, f\left(v_{n_{1}}\right)\right]$ adalah batasan untuk $f$ pada subgraf yang diinduksi oleh titik $v_{1}, v_{2}, \ldots v_{n_{1}}$. Jika terdapat suatu titik $v_{l} \in V(G)$ sedemikian sehingga $f\left(v_{l}\right)=s$ dan $f\left(N_{G}\left(v_{l}\right)\right)=r, t$, maka terdapat segmen $[[r, s, t]]$ di $f$. Notasi ini mengindikasikan bahwa pada graf $G$ terdapat suatu titik berwarna $s$ berada diantara dua titik yang berwarna $r$ dan t. Perlu diketahui bahwa $[[r, s, t]]=[[t, s, r]]$. Jika $f\left(v_{l}\right)=c \operatorname{dan} f\left(N_{G}\left(v_{l}\right)\right)=r$, maka segmen $[[r, s, r]]$ terjadi di $f$. Hal ini mengindikasikan bahwa terdapat suatu titik berwarna $s$ berada diantara dua titik berwarna $r$, atau terdapat suatu titik berderajat satu (daun) berwarna $s$ dengan warna tetangga $r$. Jika $r, s, t$ adalah elemen dari $[k]$ dengan $r \neq s$ dan $t \neq s$, maka $[[r, s, t]]$ disebut sebagai segmen yang mungkin atas himpunan $[k]$.

Proposisi 4.3. [2] Misalkan $n$ dan $k$ adalah dua bilangan bulat positif. Jika terdapat pewarnaan lokasi tetangga $k$-warna $f$ dari $P_{n}$ atau $C_{n}$, maka $n \leq \frac{1}{2}\left(k^{3}-k^{2}\right)$. Persamaan tersebut terpenuhi jika dan hanya jika tiap segmen yang mungkin atas himpunan $[k]$ terjadi paling banyak satu kali di $f$.

Bukti. Asumsikan bahwa $f$ adalah pewarnaan lokasi tetangga $k$-warna dari $G$, $G \in\left\{P_{n}, C_{n}\right\}$, untuk $k>0$. Jika $u$ dan $v$ adalah dua titik di $G$ dengan warna yang sama yaitu $i, 1 \leq i \leq k$, maka $f\left(N_{G}(u)\right) \neq f\left(N_{G}(v)\right)$. Untuk setiap $u \in V(G)$, $\left|f\left(N_{G}(u)\right)\right| \leq 2$. Oleh karena itu diperoleh

$$
\left|\left\{u|u \in V(G), f(u)=i,| f\left(N_{G}(u)\right) \mid=1\right\}\right| \leq k-1
$$

dan

$$
\left|\left\{u|u \in V(G), f(u)=i,| f\left(N_{G}(u)\right) \mid=2\right\}\right| \leq\left(\begin{array}{c}
k-1 \\
2
\end{array}\right) .
$$

Ini berarti bahwa terdapat paling banyak $(k-1)+\left(\begin{array}{l}k-1 \\ 2\end{array}\right)=\frac{1}{2}\left(k^{2}-k\right)$ titik di $G$ dengan warna $i$. Oleh karena itu, $n \leq k\left(\frac{k^{2}-k}{2}\right)$. Karena $f$ adalah suatu pewarnaan lokasi tetangga dengan $k$-pewarnaan, maka setiap titik berada pada $G \in\left\{P_{n}, C_{n}\right\}$

Jika $f$ adalah suatu pewarnaan dari $P_{t}=v_{1} v_{2} \ldots v_{t}$ dan $f^{\prime}$ adalah suatu pewarnaan dari $P_{t^{\prime}}=v_{1}^{\prime} v_{2}^{\prime} \ldots v_{t^{\prime}}^{\prime}$, maka

$$
f \oplus f^{\prime}=\left[f\left(v_{1}\right), f\left(v_{2}\right), \ldots, f\left(v_{t}\right), f^{\prime}\left(v_{1}^{\prime}\right), f^{\prime}\left(v_{2}^{\prime}\right), \ldots, f^{\prime}\left(v_{t}^{\prime}\right)\right] .
$$


Oleh karena itu $f\left(v_{t}\right) \neq f^{\prime}\left(v_{1}^{\prime}\right)$. Dengan $f \oplus f^{\prime}$ adalah suatu pewarnaan dari suatu graf lintasan $P_{t+t^{\prime}}=v_{1} \ldots v_{t} v_{1}^{\prime} \ldots v_{t^{\prime}}^{\prime}$.

Teorema 4.4. [2] Untuk suatu bilangan bulat positif $n \geq 2, \chi_{L 2}\left(P_{n}\right)=m$, dimana $m=\min \left\{k \mid k \in N, n \leq \frac{1}{2}\left(k^{3}-k^{2}\right)\right\}$. Khususnya, terdapat suatu pewarnaan lokasi tetangga dengan $m$-warna $f_{n}$ pada graf lintasan $P_{n}=v_{1} v_{2} \ldots v_{n}$ sedemikian sehingga $f_{n}\left(v_{n-1}\right)=2$ dan $f_{n}\left(v_{n}\right)=1$. Untuk $n \geq 9, f_{n}\left(v_{n-2}\right)=m$. Selanjutnya, untuk $n \geq 9$ dan $n \neq \frac{1}{2}\left(m^{3}-m^{2}\right)-1, f_{n}\left(v_{1}\right)=2, f_{n}\left(v_{2}\right)=1$.

Dari Teorema 4.1 dan Teorema 4.4 diperoleh dua akibat berikut.

Akibat 4.5. [2] Untuk $m \geq 1$ dan $n \geq 2$, diperoleh

$$
\chi_{L}\left(K_{m}+P_{n}\right)=m+\min \left\{k>0, n \leq \frac{1}{2}\left(k^{3}-k^{2}\right)\right\} .
$$

Khususnya, bilangan kromatik lokasi dari graf kipas $F_{n}$ adalah $\chi_{L}\left(K_{1}+P_{n}\right)$.

Bukti. Diberikan dua graf $K_{m}$ dan $P_{n}$. Dari Teorema 4.1 diketahui bahwa $\chi_{L}\left(G_{1}+\right.$ $\left.G_{2}\right)=\chi_{L 2}\left(G_{1}\right)+\chi_{L 2}\left(G_{2}\right)$. Akibatnya $\chi_{L}\left(K_{m}+P_{n}\right)=\chi_{L 2}\left(K_{m}\right)+\chi_{L 2}\left(P_{n}\right)$. Dari Teorema 4.4 diketahui bahwa untuk $n \geq 2$ diperoleh $\chi_{L 2}\left(P_{n}\right)=m$, di mana $m=$ $\min \left\{k \mid k>0, n \leq \frac{1}{2}\left(k^{3}-k^{2}\right)\right\}$, dan $\chi_{L 2}\left(K_{m}\right)=m$. Oleh karena itu

$$
\chi_{L}\left(K_{m}+P_{n}\right)=m+\min \left\{k \mid k \in \mathbb{N}, n \leq \frac{1}{2}\left(k^{3}-k^{2}\right)\right\} .
$$

Akibat 4.6. [2] Untuk dua bilangan bulat positif $m \geq 2$ dan $n \geq 2$, misalkan $m_{0}=\min \left\{k \mid k \in \mathbb{N}, m \leq \frac{1}{2}\left(k^{3}-k^{2}\right)\right\}$ dan $n_{0}=\min \left\{k \mid k \in \mathbb{N}, n \leq \frac{1}{2}\left(k^{3}-k^{2}\right)\right\}$. Maka, $\chi_{L}\left(P_{m}+P_{n}\right)=m_{0}+n_{0}$.

Bukti. Untuk $m \geq 2$ diketahui bahwa $\chi_{L 2}\left(P_{n}\right)=\min \left\{k \mid k \in \mathbb{N}, m \leq \frac{1}{2}\left(k^{3}-k^{2}\right)\right\}$. dan $\chi_{L 2}\left(P_{m}\right)=\min \left\{k \mid k \in \mathbb{N}, n \leq \frac{1}{2}\left(k^{3}-k^{2}\right)\right\}$ untuk $n \geq 2$. Karena $m_{0}=$ $\min \left\{k \mid k \in \mathbb{N}, m \leq \frac{1}{2}\left(k^{3}-k^{2}\right)\right\}$ dan $n_{0}=\min \left\{k \mid k \in \mathbb{N}, n \leq \frac{1}{2}\left(k^{3}-k^{2}\right)\right\}$, maka $\chi_{L 2}\left(P_{m}\right)+\chi_{L 2}\left(P_{n}\right)=m_{0}+n_{0}$. Oleh karena itu $\left.\chi_{L}\left(P_{m}+P_{n}\right)\right)=m_{0}+n_{0}$.

Selanjutnya akan ditentukan bilangan kromatik lokasi tetangga dari graf siklus. Kemudian akan ditentukan nilai untuk $\chi_{L}\left(P_{m}+C(n)\right), \chi_{L}\left(K_{m}+C(n)\right)$ dan $\chi_{L}\left(C_{m}+C(n)\right)$. Untuk setiap $n, 3 \leq n<9$, berdasarkan pewarnaan $h_{n}$ pada graf siklus $C_{n}$ berikut $h_{3}=[1,2,3], h_{4}=[1,2,3,4], h_{5}=[1,2,1,2,3]$, $h_{6}=[1,2,1,3,2,4], h_{7}=[2,1,3,2,3,2,1], h_{8}=[3,2,3,1,3,1,2,1,4]$, dapat dilihat bahwa setiap pewarnaan $h_{n}$ adalah suatu pewarnaan lokasi tetangga. Perlu diketahui bahwa $\chi_{L}\left(C_{n}\right)$ adalah tiga atau empat tergantung pada banyaknya $n$, dan $\chi_{L}\left(C_{n}\right) \leq \chi_{L 2}\left(C_{n}\right)$. Selanjutnya, $\chi_{L}\left(C_{n}\right)=\chi_{L 2}\left(C_{n}\right)$ untuk $3 \leq n<9$. Untuk kasus $n \geq 9$, diperoleh teorema berikut.

Teorema 4.7. [2] Untuk suatu bilangan bulat positif $n \geq 9$, misalkan $n_{0}=\min \{k \in$ $\left.\mathbb{N}, n \leq \frac{1}{2}\left(k^{3}-k^{2}\right)\right\}$, maka

$$
\chi_{L 2}\left(C_{n}\right)=\left\{\begin{array}{ccc}
n_{0} & \text { untuk } & n \neq \frac{1}{2}\left(n_{0}^{3}-n_{0}^{2}\right)-1 \\
n_{0}+1 & \text { untuk } & n=\frac{1}{2}\left(n_{0}^{3}-n_{0}^{2}\right)-1 .
\end{array}\right.
$$


Bukti. Misalkan $C_{n}=v_{1} v_{2} \ldots v_{n} v_{1}$. Dari Proposisi 3.2, diperoleh $\chi_{L 2}\left(C_{n}\right) \leq n_{0}$. Asumsikan bahwa $n \neq \frac{1}{2}\left(\left(n_{0}^{3}-n_{0}^{2}\right)-1\right)$. Berdasarkan Teorema 4.4, terdapat suatu pewarnaan lokasi tetangga $f_{n}$ dengan $n_{0}$-warna pada graf lintasan $P_{n}=v_{1} v_{2} \ldots v_{n}$ sedemikian sehingga $f_{n}\left(V_{1}\right)=2, f_{n}\left(V_{2}\right)=1, f_{n}\left(V_{n-1}\right)=2$. Misalkan $f_{n}$ sebagai suatu pewarnaan dari titik pada $C_{n}$. Karena $f_{n}\left(v_{1}\right) \neq f_{n}\left(v_{n}\right)$, maka $f_{n}$ adalah suatu pewarnaan sejati pada $C_{n}$. Oleh karena itu, untuk setiap $1 \leq i \leq n$, diperoleh $f_{n}\left(N_{C_{n}}\left(v_{1}\right)\right)=f_{n}\left(N_{P_{n}}\left(v_{1}\right)\right)$. Selanjutnya, $f_{n}$ adalah suatu pewarnaan lokasi tetangga pada $C_{n}$ dengan $n_{0}$-warna. Hal ini mengakibatkan bahwa $\chi_{L 2}\left(C_{n}\right)=n_{0}$.

Asumsikan bahwa $n=\frac{1}{2}\left(n_{0}^{3}-n_{0}^{2}\right)-1$. Berdasarkan Teorema 4.4, terdapat suatu pewarnaan lokasi tetangga $f_{n-1}$ dari lintasan $P_{n-1}=v_{1} v_{2} \ldots v_{n}$ sedemikian sehingga $f_{n-1}\left(V_{1}\right)=2$ dan $f_{n}\left(V_{n-1}\right)=1$. Definisikan suatu pewarnaan $f_{n^{\prime}}$ pada $C_{n}$ sebagai $f_{n}^{\prime}\left(v_{n}\right)=n_{0}+1$ dan $f_{n}^{\prime}\left(v_{i}\right)=f_{n-1}\left(v_{i}\right)$ untuk $1 \leq i \leq n-1$. Diketahui bahwa, $n_{0}+1 \in f_{n}^{\prime}\left(N_{C_{n}}\left(v_{1}\right)\right) \cap f_{n}^{\prime}\left(N_{C_{n}}\left(v_{n-1}\right)\right), f_{n}^{\prime}\left(v_{1}\right) \neq f_{n}^{\prime}\left(v_{n-1}\right)$, dan $f_{n}^{\prime}\left(N_{C_{n}}\left(v_{i}\right)\right)=f_{n-1}\left(N_{P_{n-1}}\left(v_{i}\right)\right)$ untuk setiap $2 \leq i \leq n-2$. Dengan demikian ,$f_{n}^{\prime}$ adalah suatu pewarnaan lokasi tetangga dengan $\left(n_{0}+1\right)$-warna pada $C_{n}$. Oleh karena itu, $\chi_{L 2}\left(C_{n}\right) \leq n_{0}+1$.

Akan ditunjukkan bahwa $\chi_{L 2}\left(C_{n}\right)=n_{0}$. Anggap bahwa terdapat suatu pewarnaan lokasi tetangga $f$ dengan $n_{0}$-warna pada $C_{n}$. Misalkan $V_{i}=\{x \mid$ $\left.x \in V\left(C_{n}\right), f(x)=i\right\}$. Karena $f$ adalah suatu pewarnaan lokasi tetangga , setiap kelas warna memuat paling banyak $\frac{1}{2}\left(n_{0}^{2}-n_{0}\right)$ titik. karena $n=\frac{1}{2}\left(\left(n_{0}^{3}-\right.\right.$ $\left.\left.n_{0}^{2}\right)-1\right)$, tepat satu kelas warna, misalnya $V_{1}$, berukuran $\frac{1}{2}\left(n_{0}^{2}-n_{0}\right)-1$ dan yang lainnya berukuran $\frac{1}{2}\left(n_{0}^{2}-n_{0}\right)$. Untuk setiap $2 \leq i \leq n_{0}$, misalkan $X_{i}=$ $(x, y) \mid x \in N_{C_{n}}(y), f(x)=1, f(y)=i$. Misalkan $2 \leq i \leq n_{0}$. Karena $\left|V_{i}\right|=\frac{1}{2}\left(n_{0}^{2}-\right.$ $\left.n_{0}\right)$, semua segmen yang mungkin pada bentuk $[[r, i, j]]$, dimana $r \in\left[n_{0}\right]$ dan $j \in\left[n_{0}\right]$, muncul di $f$. Dengan demikian, untuk setiap $j$ dengan $j \in\{1, i\}$, terdapat $y \in V_{i}$ sedemikian sehingga $f\left(N_{C_{n}}(y)\right)=\{1, j\}$. Juga terdapat $z \in V_{i}$ sedemikian sehingga $f\left(N_{C_{n}}(z)\right)=\{1\}$. Ini mengakibatkan $\left|X_{i}\right|=\left(n_{0}-2\right)+2=n_{0}$. Oleh karena itu $|X|=\left(n_{0}-1\right) n_{0}$, dimana $X=X_{2} \cup X_{3} \cup \ldots X_{n_{0}}$. Setiap titik $x$ dengan warna 1 mempunyai dua tetangga dan oleh karena itu $|X|=2 \mid\left\{x\left|x \in V\left(C_{n}\right), f(x)=1\right|\right.$. Ini berarti bahwa terdapat titik sebanyak $\frac{|X|}{2}=\frac{\left(n_{0}-1\right) n_{0}}{2}$ berwarna 1 .

Dari Proposisi 3.2, Teorema 4.4, dan Teorema 4.7 diperoleh akibat-akibat berikut.

Akibat 4.8. [2] Untuk dua bilangan bulat positif $m \geq 2$ dan $n \geq 3$, misalkan $m_{0}=\min \left\{k \in \mathbb{N}, m \leq \frac{1}{2}\left(k^{3}-k^{2}\right)\right\}$ dan $n_{0}=\min \left\{k \mid k \in \mathbb{N}, n \leq \frac{1}{2}\left(k^{3}-k^{2}\right)\right\}$, maka

$$
\chi_{L}\left(P_{m}+C_{n}\right)= \begin{cases}m_{0}+\chi_{L}\left(C_{n}\right) & ; \text { untuk } 3 \leq n<9 \\ m_{0}+n_{0} & ; \text { untuk } n \geq 9, n \neq \frac{1}{2}\left(n_{0}^{3}-n_{0}^{2}\right)-1 \\ m_{0}+n_{0}+1 & ; \text { untuk } n \geq 9, n=\frac{1}{2}\left(n_{0}^{3}-n_{0}^{2}\right)-1 .\end{cases}
$$

Akibat 4.9. [2] Untuk dua bilangan bulat positif $m \geq 1$ dan $n \geq 3$, misalkan $n_{0}=\min \left\{k \in \mathbb{N}, m \leq \frac{1}{2}\left(k^{3}-k^{2}\right)\right\} . M a k a$,

$$
\chi_{L}\left(K_{m}+C_{n}\right)= \begin{cases}m+\chi_{L}\left(C_{n}\right) & ; \text { untuk } 3 \leq n<9 \\ m+n_{0} & ; \text { untuk } n \geq 9, n \neq \frac{1}{2}\left(n_{0}^{3}-n_{0}^{2}\right)-1 \\ m+n_{0}+1 & ; \text { untuk } n \geq 9, n \neq \frac{1}{2}\left(n_{0}^{3}-n_{0}^{2}\right)-1 .\end{cases}
$$


Karena graf roda $W_{n} \simeq K_{1}+C_{n}$, maka bilangan kromatik lokasi graf roda $W_{n}$ dapat diperoleh dengan menghitung $\chi_{L}\left(K_{1}+C_{n}\right)$.

Akibat 4.10. [2] Untuk dua bilangan positif $m$ dan $n, 3 \leq m \leq n$, misalkan $m_{0}=\min \left\{k \in \mathbb{N}, m \leq \frac{1}{2}\left(k^{3}-k^{2}\right)\right\}$ dan $n_{0}=\min \left\{k \in \mathbb{N}, n \leq \frac{1}{2}\left(k^{3}-k^{2}\right)\right\}$, maka

$$
\chi_{L}\left(C_{m}+C n\right)= \begin{cases}\chi_{L}(m)+\chi_{L}(n) & ; \text { untuk } n<9 \\ \chi_{L}(m)+n_{0} & ; \text { untuk } m<9 \leq n, n \neq \frac{1}{2}\left(n_{0}^{3}-n_{0}^{2}\right)-1 \\ \chi_{L}(m)+n_{0}+1 & ; \text { untuk } m<9 \leq n, n=\frac{1}{2}\left(n_{0}^{3}-n_{0}^{2}\right)-1 \\ m_{0}+n_{0} & ; \text { untuk } m \geq 9, m \neq \frac{1}{2}\left(m_{0}^{3}-m_{0}^{2}\right)-1, n \neq \frac{1}{2}\left(n_{0}^{3}-n_{0}^{2}\right)-1 \\ m_{0}+n_{0}+1 & ; \text { untuk } m \geq 9, m=\frac{1}{2}\left(m_{0}^{3}-m_{0}^{2}\right)-1, n \neq \frac{1}{2}\left(n_{0}^{3}-n_{0}^{2}\right)-1 \\ m_{0}+n_{0}+1 & ; \text { untuk } m \geq 9, m \neq \frac{1}{2}\left(m_{0}^{3}-m_{0}^{2}\right)-1, n=\frac{1}{2}\left(n_{0}^{3}-n_{0}^{2}\right)-1 \\ m_{0}+n_{0}+2 & ; \text { untuk } m \geq 9, m=\frac{1}{2}\left(m_{0}^{3}-m_{0}^{2}\right)-1, n=\frac{1}{2}\left(n_{0}^{3}-n_{0}^{2}\right)-1 .\end{cases}
$$

\section{Daftar Pustaka}

[1] As'ad, Nabila. Tanpa Tahun. Aplikasi Pewarnaan Graf pada Pemecahan Masalah Penyusunan Jadwal. ITB. Bandung.

[2] Behtoei, A. 2012. The Locating Chromatic Number of the Join of Graphs. arxiv.org/abs/1112.235\%.

[3] Bondy, J.A dan U.S.R Murty. 2008. Graph Theory, Springer, United States.

[4] Chartrand, G dan Ping Zhang. 2009. Chromatic Graph Theory. CRC Press. United States.

[5] Chartrand, G dkk. The locating chromatic number of a graph. Bull. Inst.Combin. Appl. 36:89-101.

[6] Godsil, C dan Gordon Royle. 2001. Algebraic Graph Theory. Springer. New York.

[7] Hartsfield, N dan G. Ringel. 1994. Pearls in Graph Theory A Comprehensive : Introduction Revised and Augmented. Academic Press. San Diego.

[8] Husodo, A.Y. Tanpa Tahun. Aplikasi Pewarnaan Graf dalam Penyimpanan Senyawa Kimia Berbahaya. ITB. Bandung.

[9] Vasudev, C . 2006. Graph theory with Application. New Delhi. India. 